[Article]

\title{
丙烯酸分子的激发态超快预解离动力学
}

\author{
张蓉蓉秦朝朝 龙金友 杨明晖 张 冰 ${ }^{*}$ \\ (中国科学院武汉物理与数学研究所, 波谱与原子分子物理国家重点实验室, 武汉 430071; \\ 中国科学院研究生院, 北京 100049)
}

\begin{abstract}
摘要: 利用飞秒葲浦-探测技术结合飞行时间质谱(TOF-MS), 研究了丙烯酸分子被 $200 \mathrm{~nm}$ 洜浦光激发到第二 电子激发态 $\left(S_{2}\right)$ 后的超快预解离动力学. 采集了母体离子和碎片离子的时间分辨质谱信号, 并利用动力学方程 对时间分辨离子质谱信号进行拟合和分析, 揭示了预解离通道的存在. 布居在 $S_{2}$ 激发态的分子通过快速的内转 换弛豫到第一电子激发态 $\left(S_{1}\right)$, 时间常数为 $210 \mathrm{fs}$, 随后再经内转换从 $S_{1}$ 态驰豫到基态 $\left(S_{0}\right)$ 的高振动态, 时间常 数为 $1.49 \mathrm{ps}$. 分子最终在基态高振动态势能面上发生 $\mathrm{C}-\mathrm{C}$ 键和 $\mathrm{C}-\mathrm{O}$ 键的断裂, 分别解离生成 $\mathrm{H}_{2} \mathrm{C}=\mathrm{CH}$ 和 $\mathrm{HOCO} 、 \mathrm{H}_{2} \mathrm{C}=\mathrm{CHCO}$ 和 $\mathrm{OH}$ 中性碎片, 对应的预解离时间常数分别约为 4 和 $3 \mathrm{ps}$. 碎片离子的产生有两个途 径, 分别来自于母体离子的解离和基态高振动态势能面上中性碎片的电离.
\end{abstract}

关键词: 时间分辨质谱; 超快动力学; 原浦-探测; 飞行时间质谱; 内转换 中图分类号: 0644

\section{Ultrafast Predissociation Dynamics of Excited State of Acrylic Acid}

\author{
ZHANG Rong-Rong $\quad$ QIN Chao-Chao ～LONG Jin-You YANG Ming-Hui $\quad$ ZHANG Bing* \\ (State Key Laboratory of Magnetic Resonance and Atomic and Molecular Physics, Wuhan Institute of Physics and Mathematics, \\ Chinese Academy of Sciences, Wuhan 430071, P. R. China; Graduate University of Chinese Academy of Sciences,
} Beijing 100049, P. R. China)

\begin{abstract}
The ultrafast predissociation dynamics of acrylic acid after excitation to the second electronically excited state $\left(S_{2}\right)$ with a $200 \mathrm{~nm}$ pump pulse were studied using a femtosecond pump-probe technique combined with time-of-flight mass spectroscopy (TOF-MS). The time-resolved mass spectra signals of the parent ion and fragment ions were collected. By using the kinetic equations to fit and analyze the time-resolved mass spectra ion signals, the existence of the predissociation channel was revealed. The excited molecule populated in the $S_{2}$ state decayed to the first electronically excited state $\left(S_{1}\right)$ through a fast internal conversion process over a period of $210 \mathrm{fs}$. The excited molecule populated on the $S_{1}$ state then decayed to the vibrationally hot ground state $\left(S_{0}\right)$ through another internal conversion process over a period of 1.49 ps. Finally, on the vibrationally hot ground state surface, the molecule dissociated to the neutral fragments, $\mathrm{H}_{2} \mathrm{C}=\mathrm{CH}$ and $\mathrm{HOCO}, \mathrm{H}_{2} \mathrm{C}=\mathrm{CHCO}$ and $\mathrm{OH}$ via $\mathrm{C}-\mathrm{C}$ bond fission and $\mathrm{C}-\mathrm{O}$ bond fission, respectively. The corresponding predissociation time constants were determined to be approximately 4 and 3 ps, respectively. The generation of fragment ions can occur in two ways, both from the dissociation of the parent ion and the ionization of the neutral fragments on the vibrationally hot ground state surface.
\end{abstract}

Key Words: Time-resolved mass spectrum; Ultrafast dynamics; Pump-probe; Time-of-flight mass spectroscopy; Internal conversion

Received: November 23, 2011; Revised: December 29, 2011; Published on Web: January 12, 2012.

"Corresponding author. Email: bzhang@wipm.ac.cn; Tel: +86-27-87197441; Fax: +86-27-87198491.

The project was supported by the National Natural Science Foundation of China (20903116) and Knowledge Innovation Foundation of Chinese Academy of Science (KJCX1-YW-N30).

国家自然科学基金(20903116)和中国科学院知识创新基金(KJCX1-YW-N30)资助项目

(C) Editorial office of Acta Physico-Chimica Sinica 


\section{Introduction}

The real-time investigation of the ultrafast dynamics of excited molecules in the gas phase has attracted a great deal of attentions over the last two decades. ${ }^{1-4}$ With the development of ultrashort-pulse laser technology, ${ }^{5}$ femtosecond pump-probe technique has been proved to be a powerful tool to study the ultrafast phenomena and obtain new insights into the detailed mechanisms of excited molecules. ${ }^{6}$ In a typical pump-probe experiment, a pump pulse excites the molecule to an excited state and a second delayed probe pulse monitors the change of the population in the excited state. By varying the time delay between the pump and probe pulses, it is possible to assemble measurements as a function of delay time. The time-dependent population can reveal the ultrafast relaxation processes ${ }^{7}$ such as internal conversion (IC) and intersystem crossing (ISC).

The gas-phase photochemistry of unsaturated carboxylic acids has been the subject of numerous interests and investigations. ${ }^{8-16}$ As the smallest $\alpha, \beta$-unsaturated carboxylic acid, acrylic acid $\left(\mathrm{H}_{2} \mathrm{C}=\mathrm{CHCOOH}\right)$ is an ideal system for investigating photochemistry of this kind of molecules and provides an important dynamic model for studying configuration interactions between $\mathrm{C}=\mathrm{C}$ and $\mathrm{C}=\mathrm{O}$ double bonds. The ultraviolet photodissociation of acrylic acid has been studied experimentally and theoretically in some detail. ${ }^{12-22}$ Several processes have been proposed as possible dissociation pathways:

$$
\begin{aligned}
& \mathrm{H}_{2} \mathrm{C}=\mathrm{CHCOOH}+h v \rightarrow \mathrm{H}_{2} \mathrm{C}=\mathrm{CH}+\mathrm{HOCO} \\
& \mathrm{H}_{2} \mathrm{C}=\mathrm{CHCOOH}+h v \rightarrow \mathrm{H}_{2} \mathrm{C}=\mathrm{CHCO}+\mathrm{OH} \\
& \mathrm{H}_{2} \mathrm{C}=\mathrm{CHCOOH}+h v \rightarrow \mathrm{H}_{2} \mathrm{C}=\mathrm{CH}_{2}+\mathrm{CO}_{2} \\
& \mathrm{H}_{2} \mathrm{C}=\mathrm{CHCOOH}+h v \rightarrow \mathrm{H}_{2} \mathrm{C}=\mathrm{CHOH}+\mathrm{CO}
\end{aligned}
$$

Reactions (1) and (2) involve the cleavage of single bonds $\mathrm{C}-$ $\mathrm{C}$ and $\mathrm{C}-\mathrm{O}$, respectively, while reactions (3) and (4) are decarboxylation and decarbonylation processes.

Rosenfeld and Weiner ${ }^{12}$ studied the photodissociation dynamics of acrylic acid at 248 and $193 \mathrm{~nm}$ using infrared fluorescence technique and concluded that the decarboxylation was the primary pathway at both wavelengths. On the basis of the mass fragmentation spectral data, Miyoshi et al. ${ }^{19}$ have pointed out that, in addition to the $\mathrm{C}-\mathrm{C}$ bond fission, reactions (2) and (4) occurred after excitation at $193 \mathrm{~nm}$. Afterwards, Kitchen et $a l .{ }^{17}$ carried out an intensive study of acrylic acid upon $193 \mathrm{~nm}$ irradiation in a cross laser-molecular beam apparatus by measuring the photofragment velocity distributions. They only observed products which resulted from primary $\mathrm{C}-\mathrm{O}$ and $\mathrm{C}-\mathrm{C}$ bond fissions, while decarboxylation was the minor channel of dissociation. However, their experimental data were still not enough to precisely describe the mechanism for how the dissociation happened. Recently, in the photodissociation study of acrylic acid excitation with ArF (193 nm) laser carried out by Upadhyaya et al., ${ }^{13}$ the initially prepared $S_{2}$ state underwent nonradiative transitions to $S_{1}$ state, where the molecule subsequently dissociated to give $\mathrm{OH}$ fragments and a risetime of 2 $\mu$ s was seen from the time-resolved fluorescence signal. However, the lifetime of $S_{2}$ and $S_{1}$ states was not determined due to the time resolution limitation of the excimer laser. The dissociation time constant and mechanism also need to be further confirmed. Apart from the experimental studies, Fang and $\mathrm{Liu}^{22} \mathrm{de}-$ termined the dissociation of acrylic acid to $\mathrm{CH}_{3} \mathrm{CH}+\mathrm{CO}_{2}$, $\mathrm{CH}_{2} \mathrm{CHOH}+\mathrm{CO}, \mathrm{CH}_{2} \mathrm{CH}+\mathrm{COOH}$, and $\mathrm{CH}_{2} \mathrm{CHCO}+\mathrm{OH}$ in the ground state surface as well as in the excited state surface using $a b$ initio quantum chemical methods after excitation to $S_{2}$ state. They proposed the most probable dissociation mechanism, but no sufficient experimental evidence to support their calculated results. It is obvious that the previous studies of acrylic acid were mainly focused on the determination of the dissociation channels. However, the researchers are still not clear about how the dissociation happens, what intermediate states and ultrafast processes involved and what kind of dissociation is (direct dissociation or predissociation). Femtosecond time-resolved experiments can figure out these questions very well.

Therefore, the femtosecond time-resolved study of acrylic acid after UV excitation of $200 \mathrm{~nm}$ is reported in this paper. We measure the mass spectra signals of the parent ion and fragment ions as a function of the delay time. How the evaluation of the excited molecule over time after preparing the optically bright $S_{2}\left({ }^{1} \pi \pi^{*}\right)$ state will be identified and the mechanism of the generation of the fragment ions will be discussed in detail. Moreover, we will try to determine the predissociation time constant for different dissociation pathways. The goal of this research is attempted to give a clear description of the ultrafast dynamics and dissociation mechanism of acrylic acid via $S_{2}$ excited state.

\section{Experimental}

The experimental setup consists of a regenerative amplified Ti:sapphire femtosecond laser system (Coherent Int., America), a molecular beam apparatus, a time-of-flight mass spectrometer (TOF-MS), and a two-dimensional (2D) position sensitive detector. The femtosecond laser system has been described in detail elsewhere. ${ }^{23}$ Briefly, it produces a pulse of 45 fs duration centered at $800 \mathrm{~nm}$ with maximum energy of $1 \mathrm{~mJ} \cdot$ pulse $^{-1}$ at 1 $\mathrm{kHz}$ repetition rate. This fundamental light was frequency doubled in a $0.5 \mathrm{~mm}$ thick BBO crystal (type I, cut angle $29.2^{\circ}$ ) to generate the second harmonic $400 \mathrm{~nm}$ pulse. The $266 \mathrm{~nm}$ probe pulse (third harmonic) was generated in a $0.2 \mathrm{~mm}$ thick BBO crystal (type I, cut angle $44.3^{\circ}$ ) by sum frequency mixing of the second harmonic and the fundamental, while the $200 \mathrm{~nm}$ pump pulse (fourth harmonic) was generated in a $0.2 \mathrm{~mm}$ thick BBO crystal (type I, cut angle $64.7^{\circ}$ ) by sum frequency mixing of the third harmonic and the fundamental. The pump and probe beams with vertical polarization were merged by a dichroic mirror and directed into the molecular beam chamber. The time delay between the pump and probe pulses was accurately monitored by a computer-controlled linear translation stage (PI, M-126.CG1, Germany).

The experiment was performed in a homebuilt apparatus, 
which has been described elsewhere. ${ }^{24-26}$ The liquid sample (acrylic acid, $99.9 \%$ purity), typically $5 \%$ seeded in helium carrier gas at a background pressure of $2 \times 10^{5} \mathrm{~Pa}$, was expanded through a pulsed valve (Parker, General Valve, America) with the aperture $0.6 \mathrm{~mm}$ to generate a pulsed molecular beam. The molecular beam was skimmed and introduced into the ionization chamber where it intersected perpendicularly with the pump and probe laser beams in the extraction field region of the TOF-MS to produce the ions. The field-free region (360 $\mathrm{mm}$ ) of the TOF-MS was shielded with a $\mu$-metal tube to suppress outer magnetic fields. The generated ions were monitored by the detector assembly consists of a dual microchannel plate (MCP, Photek, Britain) and a fast P47 phosphor screen (3040FM, Galileo Electro-Optic Corp, America). A photomultiplier tube (PMT, 931A, Hamamatsu, Japan) is mounted behind the screen to collect TOF mass spectra. The output mass spectra signal was displayed by a digital oscilloscope (Tektronix, TDS 2012, America) and then transferred to a computer that controlled the experiment.

\section{Results and discussion}

The TOF mass spectrum of acrylic acid are obtained at the temporal overlap of the $200 \mathrm{~nm}$ pump and the $266 \mathrm{~nm}$ probe light, as shown in Fig.1. The peaks of parent ion and fragment ions have been observed in the spectrum. The peaks yielded at $m / e$ of $72,55,45,27$, and 17 corresponding to $\mathrm{C}_{3} \mathrm{H}_{4} \mathrm{O}_{2}^{+}$parent ion, $\mathrm{H}_{2} \mathrm{C}=\mathrm{CHCO}^{+}, \mathrm{HOCO}^{+}, \mathrm{H}_{2} \mathrm{C}=\mathrm{CH}^{+}$, and very weak $\mathrm{OH}^{+}$ fragment ions, respectively. The TOF mass spectra show that
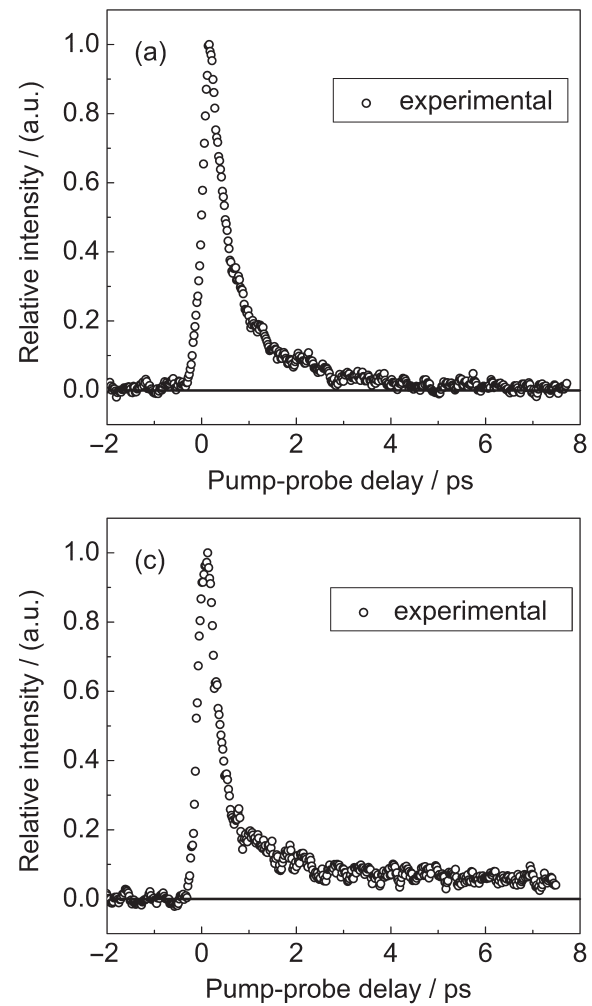

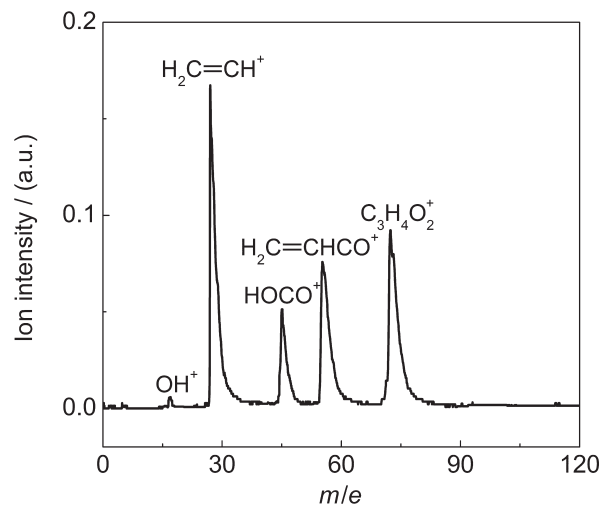

Fig.1 TOF mass spectrum of acrylic acid obtained at the temporal overlap of $200 \mathrm{~nm}$ pump and $266 \mathrm{~nm}$ probe light

the cleavage of $\mathrm{C}-\mathrm{C}$ bond and $\mathrm{C}-\mathrm{O}$ bond happened after excitation of acrylic acid.

Fig. 2 shows the recorded time-resolved mass spectra ion signals of $\mathrm{C}_{3} \mathrm{H}_{4} \mathrm{O}_{2}^{+}, \mathrm{H}_{2} \mathrm{C}=\mathrm{CHCO}^{+}, \mathrm{HOCO}^{+}$, and $\mathrm{H}_{2} \mathrm{C}=\mathrm{CH}^{+}$as a function of the pump-probe delay time. The signal of $\mathrm{OH}^{+}$fragment ion is too weak to extract the time-resolved ion signal. It is obvious that the signal profile of fragment ions shows different decay behavior compared to parent ion after several picoseconds. The dynamics concealed in the decay of these ion signals will be discussed later by our kinetic equation fitting and analysis.

Since the ionization energy (IE) of acrylic acid is $10.77 \mathrm{eV},{ }^{27}$ the ionization of acrylic acid can be obtained by one $200 \mathrm{~nm}$ $(6.32 \mathrm{eV})$ photon pump and one more $266 \mathrm{~nm}(4.65 \mathrm{eV})$ pho-
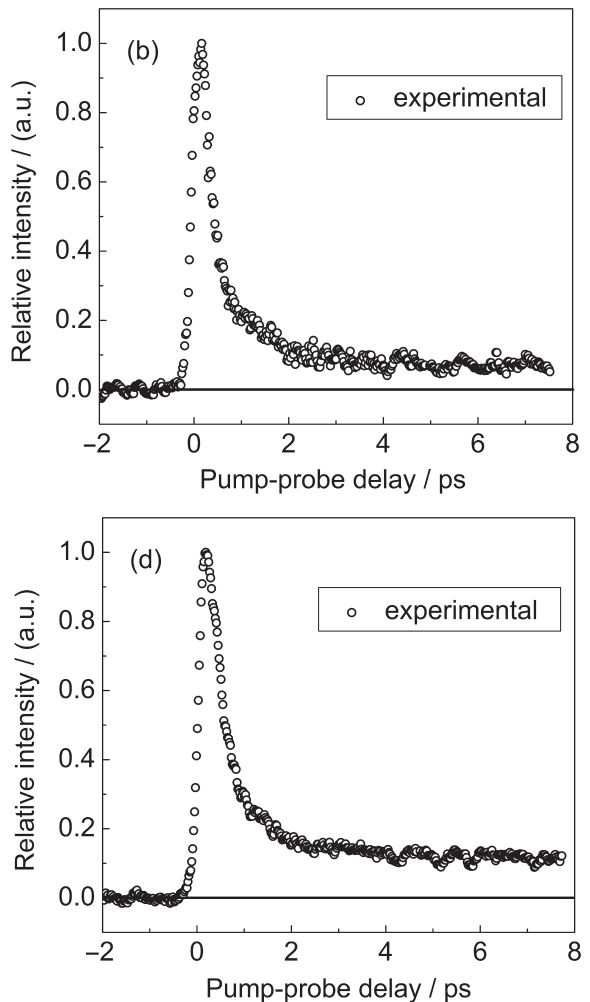

Fig.2 Time-resolved mass spectra ion signals recorded as a function of the pump-probe delay (a) $\mathrm{C}_{3} \mathrm{H}_{4} \mathrm{O}_{2}{ }^{+}$, (b) $\mathrm{H}_{2} \mathrm{C}=\mathrm{CHCO}^{+}$, (c) $\mathrm{HOCO}^{+}$, (d) $\mathrm{H}_{2} \mathrm{C}=\mathrm{CH}^{+}$; The black line is the zero baseline. 
ton probe. It is believed that the excitation of acrylic acid at $200 \mathrm{~nm}$ is populated on the $S_{2}\left({ }^{1} \pi \pi^{*}\right)$ state centered at vinyl group with an admixture of $\pi^{*}(\mathrm{C}=\mathrm{C}) / \pi^{*}(\mathrm{C}=\mathrm{O})$ character, which is confirmed by the emission spectrum reported by Arendt et al. ${ }^{10}$ The $S_{1}$ state of acrylic acid is of $n \pi^{*}$ character localized on the carbonyl group, which is a dissociative state. ${ }^{13}$ From the theoretical calculation of acrylic acid, Fang and $\mathrm{Liu}^{22}$ concluded that after the molecule populated on the $S_{2}$ state, the system may decay through three radiationless routes, internal conversion (IC) to $S_{0}$, to $S_{1}$ and intersystem crossing (ISC) to $T_{2}$. Generally speaking, an intersystem crossing from excited singlet to triplet state occurs with very low efficiency in the carbonyl compounds. ${ }^{28}$ Moreover, Upadhyaya et al ${ }^{13}$ reported that when $\left(\pi, \pi^{*}\right)$ transition of acrylic acid is excited by $\operatorname{ArF}(193$ $\mathrm{nm}$ ) laser pulses, the initially prepared $S_{2}$ state through nonradioactive transition to higher vibrational levels of the $S_{1}$ state is the dominant pathway because it seems unlikely that a spin-forbidden ISC to $T_{2}$ state can compete with spin-allowed IC to $S_{1}$ state.

In our experiment, the ground state acrylic acid absorbs one $200 \mathrm{~nm}$ photon to the $S_{2}$ excited state, then the excited molecule can be ionized by absorbing one $266 \mathrm{~nm}$ probe photon forming parent ion. According to the discussion above, the $S_{2}$ state most probably through IC decays to the $S_{1}$ state and $S_{0}$ state, the $S_{1}$ state then relaxes to the $S_{0}$ state, here $S_{1}$ and $S_{0}$ refer to the higher vibrational levels of the $S_{1}$ state and the vibrationally hot ground state, respectively. The excited molecule populated on the $S_{1}$ state can also be ionized by absorbing probe light, while in the $S_{0}$ state, the molecule could not be directly ionized since very high energy required for ionization according to Franc-Condon principle. Thus, we believe that the parent ion comes from the ionization of $S_{2}$ and $S_{1}$ excited states. In order to confirm the proposed complex kinetic schemes, we use coupled kinetic equations to fit the time profile of parent ion. It is known that the photoionization cross sections of $S_{2}$ and $S_{1}$ states depend on the electronic configuration of these states and cation state. Thus, the relative ratio of ionization cross section of the two states is an unknown quantity. We assume that the relative ratio of ionization cross section of the $S_{1}$ and $S_{2}$ states is $P_{1}$ and the possibility of simultaneous excitation of the $S_{1}$ state is neglected in our fitting processes. Then, the coupled kinetic equations are given as follows:

$$
\begin{aligned}
& \mathrm{d}\left[\mathrm{ion}_{\mathrm{p}}\right] / \mathrm{d} t=\sigma_{\mathrm{i}} I_{\text {probe }}(t)\left\{P_{1}\left[S_{1}\right]+\left[S_{2}\right]\right\} \\
& \mathrm{d}\left[S_{2}\right] / \mathrm{d} t=-\left(1 / \tau_{1}+1 / \tau_{3}\right)\left[S_{2}\right]+\sigma_{\mathrm{a}} I_{\text {pump }}(t)\left[S_{0}\right] \\
& \mathrm{d}\left[S_{1}\right] / \mathrm{d} t=\left(1 / \tau_{1}\right)\left[S_{2}\right]-\left(1 / \tau_{2}\right)\left[S_{1}\right] \\
& \mathrm{d}\left[S_{0}\right] / \mathrm{d} t=\left(1 / \tau_{3}\right)\left[S_{2}\right]+\left(1 / \tau_{2}\right)\left[S_{1}\right]-\sigma_{\mathrm{a}} I_{\text {pump }}(t)\left[S_{0}\right]
\end{aligned}
$$

where $\left[\right.$ ion $\left._{\mathrm{p}}\right],\left[S_{2}\right],\left[S_{1}\right]$, and $\left[S_{0}\right]$ represent the relative population of parent ion, second excited state, first excited state, and vibrationally hot ground state of acrylic acid, respectively. $\mathrm{d}[\mathrm{X}] / \mathrm{d} t\left(\mathrm{X}=\mathrm{ion}_{\mathrm{p}}, S_{2}, S_{1}\right.$, and $\left.S_{0}\right)$ represents the relative population changing over time. $\sigma_{\mathrm{i}}$ is the photoionization cross section and $\sigma_{\mathrm{a}}$ is the photoabsorption cross section. $I_{\text {pump }}(t)$ and $I_{\text {probe }}(t)$ are the pump and probe laser intensities, respectively. $1 / \tau_{1}, 1 / \tau_{2}$, and $1 / \tau_{3}$ represent the $S_{2}-S_{1}, S_{1}-S_{0}$, and $S_{2}-S_{0}$ IC rates, respectively. Fluorescence from $S_{2}$ and vibrationally excited $S_{1}$ states is ruled out due to their very low quantum yield.

The fitting results of the time-resolved parent ion signal using kinetic equations are shown in Fig.3. Open circles are the experimental results and solid lines are the fitting results. The kinetic fitting is consistent with our experimental data very well. It gives time constants of $\tau_{1}=210 \mathrm{fs}, \tau_{2}=1.49 \mathrm{ps}, P_{1}=0.21$, and $\tau_{3}$ is very long relative to $\tau_{1}$ and $\tau_{2}$. The results indicate that IC of the $S_{2}$ state to the vibrationally hot $S_{0}$ state is negligible and the relative ratio of ionization cross section of $S_{1}$ and $S_{2}$ states is 0.21 . The fast red component ( $210 \mathrm{fs}$ ) in the time profile corresponding to the lifetime of $S_{2}$ state is mainly decayed through $S_{2}-S_{1}$ IC, while the slow purple component (1.49 ps) corresponding to the lifetime of $S_{1}$ state is possibly decayed through $S_{1}-S_{0}$ IC.

In Fig.2(b-d), the time profiles of the fragment ions have same kinetic behavior as parent ion at the beginning of about 2 ps, but after that the fragment ion signals show almost no decay even at long delay time, which suggests that the generation of the fragment ions should have two different originations, from the dissociation of parent ion and the ionization of neutral fragment. From kinetic analysis of the parent ion signal, the results have shown that the excited molecule was finally relaxed to the vibrationally hot ground state. Thus, we concluded that the dissociation of acrylic acid molecule should happen on the vibrationally hot ground state surface, which is the type of predissociation. This can be supported by the theoretical study of the photodissociation of acrylic acid carried by Fang and Liu. ${ }^{22}$ They pointed out that on the ground-state surface is the most probable pathway for the cleavage of $\mathrm{C}-\mathrm{C}$ and $\mathrm{C}-\mathrm{O}$ bonds, producing $\mathrm{H}_{2} \mathrm{C}=\mathrm{CH}$ and $\mathrm{HOCO}, \mathrm{H}_{2} \mathrm{C}=\mathrm{CHCO}$ and $\mathrm{OH}$, respectively. Based on the above discussion, the signal change of fragment ion over time can be expressed as the signal change of parent ion over time superimpose the ion signal change on the vibrationally hot ground state surface over time. The kinetic equation is given as follows,

$$
\mathrm{d}\left[\mathrm{ion}_{\mathrm{f}}\right] / \mathrm{d} t=\mathrm{d}\left[\operatorname{ion}_{\mathrm{p}}\right] / \mathrm{d} t+P_{2} \mathrm{~d}\left[S_{0}\right] / \mathrm{d} t
$$

where $\mathrm{d}[\mathrm{X}] / \mathrm{d} t\left(\mathrm{X}=\mathrm{ion}_{\mathrm{f}}\right.$, ion $_{\mathrm{p}}$, and $\left.S_{0}\right)$ is the signal of fragment ion, parent ion, and ion on the vibrationally hot ground state

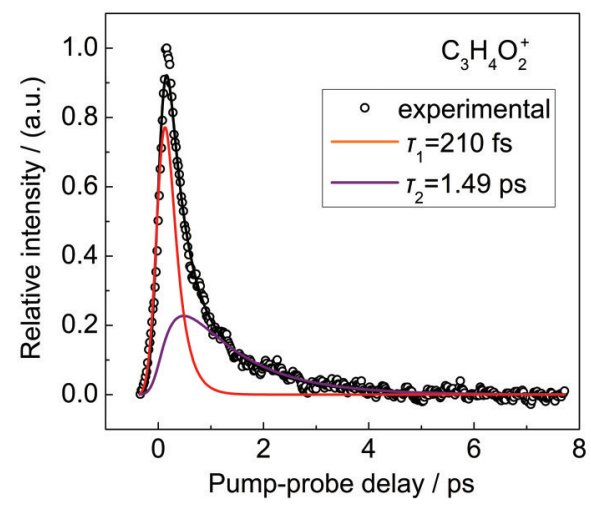

Fig.3 Fitting results of the time-resolved parent ion signal using kinetic equations 

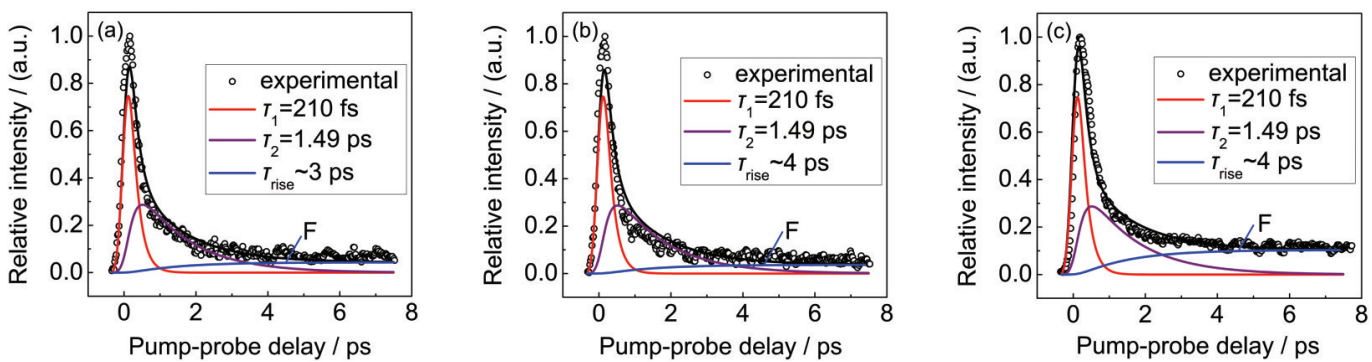

Fig.4 Kinetic fitting of the time-resolved signal of fragment ions

(a) $\mathrm{H}_{2} \mathrm{C}=\mathrm{CHCO}^{+}$, (b) $\mathrm{HOCO}^{+}$, (c) $\mathrm{H}_{2} \mathrm{C}=\mathrm{CH}^{+}$

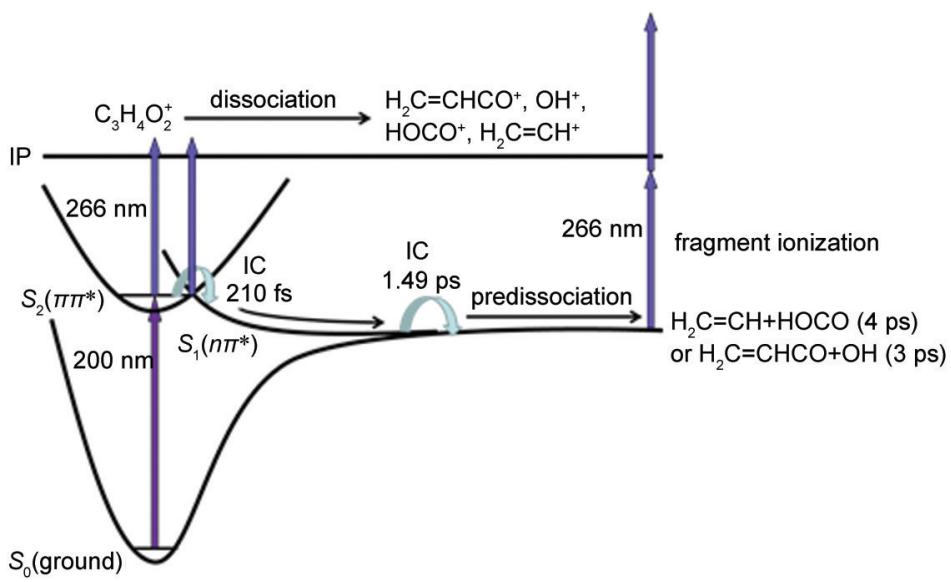

Fig.5 A schematic diagram of ultrafast dynamic processes involved in the excitation of acrylic acid with $200 \mathrm{~nm}$ pump and $266 \mathrm{~nm}$ probe

surface changing over delay time, respectively. $P_{2}$ is the intensity ratio of two components, $\mathrm{d}\left[S_{0}\right] / \mathrm{d} t$ and $\mathrm{d}\left[\mathrm{ion}_{\mathrm{p}}\right] / \mathrm{d} t$. Since $\mathrm{d}\left[\mathrm{ion}_{\mathrm{p}}\right] / \mathrm{d} t$ is a known quantity, using its fitting results shown in Fig. 3 and according to the kinetic equation (6), the time-resolved profiles of fragment ions (Fig.2(b-d)) can be easily fitted and the results are displayed in Fig.4. Open circles are the experimental results and solid lines are the fitting results.

As shown in Fig.4, the kinetic fitting results of each fragment ion signal consists of three components, the two of which (red and purple components) are the same as parent ion, corresponding to the internal conversion from $S_{2}$ to $S_{1}$ state (210 fs) and the internal conversion from $S_{1}$ to vibrationally hot $S_{0}$ state (1.49 ps). The third blue component shows an exponential increase $\left(\tau_{\text {rise }}\right)$ followed by a long-life part labeled as F, which reflects the dissociation of acrylic acid on the vibrationally hot $S_{0}$ state and the ionization of neutral fragments forming long-life fragment ions, respectively. $\tau_{\text {rise }}$ describes the predissociation lifetime and $\mathrm{F}$ corresponds to the lifetime of the fragment ion. At long time delays, $\mathrm{F}$ is the only part remaining after all other components have decayed to zero. It should be noted that the fragment ion is not stable infinitely. It only means that it does not decay appreciably on the time scale of our experiment (i.e., approximately hundreds of picoseconds). According to our kinetic fitting results in Fig.4, the time constant of predissociation for $\mathrm{C}-\mathrm{C}$ bond cleavage to $\mathrm{H}_{2} \mathrm{C}=\mathrm{CH}$ and $\mathrm{HOCO}$ is approximately 4 ps, while for $\mathrm{C}-\mathrm{O}$ bond cleavage to $\mathrm{H}_{2} \mathrm{C}=\mathrm{CHCO}$ and $\mathrm{OH}$ is about 3 ps. The values of $P_{2}$ are also determined in our kinetic fitting, which are approximately $0.02,0.02$, and 0.05 for $\mathrm{H}_{2} \mathrm{C}=\mathrm{CHCO}^{+}, \mathrm{HOCO}^{+}$, and $\mathrm{H}_{2} \mathrm{C}=\mathrm{CH}^{+}$, respectively.

Summarizing the above analyses, the involved ultrafast dynamic processes of acrylic acid with the pump pulse of $200 \mathrm{~nm}$ and the probe pulse of $266 \mathrm{~nm}$ are revealed and shown in Fig.5. Acrylic acid is excited to the optically bright $S_{2}\left(\pi \pi^{*}\right)$ by absorbing one $200 \mathrm{~nm}$ photon, the $S_{2}$ state rapidly decays via internal conversion (IC) to the lower lying repulsive $S_{1}\left(n \pi^{*}\right)$ state in 210 fs followed by another IC to the vibrationally hot $S_{0}$ state in $1.49 \mathrm{ps}$. The molecule populated on the $S_{2}$ and $S_{1}$ excited states can be ionized forming parent ion by absorbing $266 \mathrm{~nm}$ probe light. Then cleavage of $\mathrm{C}-\mathrm{C}$ and $\mathrm{C}-\mathrm{O}$ bonds happened in the parent ion, generating fragment ions of $\mathrm{H}_{2} \mathrm{C}=$ $\mathrm{CHCO}^{+}, \mathrm{HOCO}^{+}, \mathrm{H}_{2} \mathrm{C}=\mathrm{CH}^{+}$, and $\mathrm{OH}^{+}$. On the vibrationally hot $S_{0}$ surface, the populated molecule eventually via predissociation mechanism dissociating to neutral fragments $\mathrm{H}_{2} \mathrm{C}=\mathrm{CH}$ and $\mathrm{HOCO}$ through $\mathrm{C}-\mathrm{C}$ bond cleavage and $\mathrm{H}_{2} \mathrm{C}=\mathrm{CHCO}$ and $\mathrm{OH}$ through $\mathrm{C}-\mathrm{O}$ bond cleavage. The predissociation time constant is about 4 ps for $\mathrm{C}-\mathrm{C}$ bond fission and $3 \mathrm{ps}$ for $\mathrm{C}-\mathrm{O}$ bond fission. Afterwards, the neutral fragments can be easily ionized by absorbing probe photons forming the long lifetime fragment ions.

\section{Conclusions}

We have demonstrated the use of femtosecond pump-probe technique combining with time-of-flight mass spectroscopy to study the ultrafast predissociation dynamics of acrylic acid. 
The predissociation channel was observed when acrylic acid was excited to the optically bright $S_{2}$ state by absorption of one $200 \mathrm{~nm}$ photon. The molecule populated on the $S_{2}$ excited state rapidly decays via internal conversion to the lower lying $S_{1}$ state in 210 fs followed by another internal conversion to the vibrationally hot $S_{0}$ state in $1.49 \mathrm{ps}$, and from where the molecule subsequently dissociates to neutral fragments $\mathrm{H}_{2} \mathrm{C}=\mathrm{CH}$ and $\mathrm{HOCO}$ in approximately $4 \mathrm{ps}, \mathrm{H}_{2} \mathrm{C}=\mathrm{CHCO}$ and $\mathrm{OH}$ in about 3 ps. Two originations of the fragment ions were clarified, which were from the dissociation of parent ion and from the ionization of neutral fragments via predissociation mechanism.

\section{References}

(1) Zewail, A. H. J. Phys. Chem. A 2000, 104, 5660.

(2) Bernardi, F.; Olivucci, M. M.; Robb, M. A. Chem. Soc. Rev. 1996, 25, 321.

(3) Schwalb, N. K.; Temps, F. J. Am. Chem. Soc. 2007, 129, 9272.

(4) Kwok, W. M.; Ma, C. S.; Phillips, D. L. J. Am. Chem. Soc. 2008, 130, 5131.

(5) Fork, R. L.; Greene, B. I.; Shank, C. V. Appl. Phys. Lett. 1981, 38,671 .

(6) Zewail, A. H. Angew. Chem. Int. Edit. 2000, 39, 2586.

(7) Domcke, W.; Stock, G. Adv. Chem. Phys. 1997, 100, 1.

(8) Lee, A. M. D.; Coe, J. D.; Ullrich, S.; Ho, M. L.; Lee, S. J.; Cheng, B. M.; Zgierski, M. Z.; Chen, I. C.; Martinez, T. J.; Stolow, A. J. Phys. Chem. A 2007, 111, 11948.

(9) Osborne, M. C.; Li, Q.; Smith, I. W. M. Phys. Chem. Chem. Phys. 1999, 1, 1447.

(10) Arendt, M. F.; Browning, P. W.; Butler, L. J. J. Chem. Phys. 1995, 103, 5877.

(11) Singleton, D. L.; Paraskevopoulos, G.; Irwin, R. S. J. Phys. Chem. 1990, 94, 695.
(12) Rosenfeld, R. N.; Weiner, B. R. J. Am. Chem. Soc. 1983, 105, 6233.

(13) Upadhyaya, H. P.; Kumar, A.; Naik, P. D.; Sapre, A. V.; Mittal, J. P. J. Chem. Phys. 2002, 117, 10097.

(14) Reguero, M.; Olivucci, M.; Bernardi, F.; Robb, M. A. J. Am. Chem. Soc. 1994, 116, 2103.

(15) Fang, W. H. J. Am. Chem. Soc. 1999, 121, 8376.

(16) Aquilante, F.; Barone, V.; Roos, B. O. J. Chem. Phys. 2003, 119, 12323.

(17) Kitchen, D. C.; Forde, N. R.; Butler, L. J. J. Phys. Chem. A 1997, 101, 6603.

(18) Forman, R. L.; MacKinnon, H. M.; Ritchie, P. D. J. Chem. Soc. C 1968, 2013.

(19) Miyoshi, A.; Matsui, H.; Washida, N. J. Chem. Phys. 1994, 100, 3532.

(20) Ruelle, P. J. Comput. Chem. 1987, 8, 158.

(21) Fang, W. H. Chem. Phys. Lett. 2000, 325, 683.

(22) Fang, W. H.; Liu, R. Z. J. Am. Chem. Soc. 2000, 122, 10886.

(23) Wei, Z. R.; Zhang, F.; Wang, Y. M.; Zhang, B. Chin. J. Chem. Phys. 2007, 20, 419. [魏振荣, 张 峰, 王艳梅, 张 冰. 化学物理学报, 2007, 20, 419.]

(24) Chen, Y.; Zhang, C. H.; Cao, Z. Z.; Zhang, B. Acta Phys. -Chim. Sin. 2008, 24, 844. [陈荫, 张昌华, 曹振洲, 张冰. 物理化 学学报, 2008, 24, 844.]

(25) Zhang, F.; Cao, Z. Z.; Qin, X.; Liu, Y. Z.; Wang, Y. M.; Zhang, B. Acta Phys. -Chim. Sin. 2008, 24, 1335. [张 锋, 曹振洲, 覃 晓, 刘玉柱, 王艳梅, 张 冰. 物理化学学报, 2008, 24, 1335.]

(26) Wang, Y. M.; Zhang, S.; Wei, Z. R.; Zhang, B. Chem. Phys. Lett. 2009, $468,14$.

(27) Katrib, A.; Rabalais, J. W. J. Phys. Chem. 1973, 77, 2358.

(28) Turro, N. J. Modern Molecular Photochemistry; Benjamin/ Cummings: Menlo Park, 1978. 